\title{
Factors determining the profitability of rice farming in Bangladesh
}

\section{Tahmina Akter ${ }^{1},{ }^{凶}$ Mst. Tania Parvin², Farhana Arefeen Mila ${ }^{2}$ and Ashrafun Nahar ${ }^{2}$}

${ }^{1}$ Department of Agricultural Economics, Faculty of Agricultural Economics and Rural Sociology, Bangladesh Agricultural University, Mymensingh-2202, Bangladesh

${ }^{2}$ Department of Agribusiness, Faculty of Agricultural Economics and Rural Development, Bangabandhu Sheikh Mujibur Rahman Agricultural University, Salna, Gazipur-1706, Bangladesh



(C2019 by authors and BAURES. This work is licensed under the Creative Commons Attribution International License (CC By 4.0).

\section{Introduction}

Rice (Oryza Sativa L.) is one of the dominant cereal dietary items of almost 15 million farm families (BBS, 2015, p. 141) in Bangladesh. It provides half of agricultural GDP, one-sixth of rural household income, half of the rural employment (nearly $48 \%$ ), two-thirds of per capita daily calorie intake, and half of per capita daily protein intake (Rahman et al., 2016, p. 180). Rice is grown on about 24.21 million acres (BBS, 2015, p. 144) which have remained almost stable over the past three decades. About 81 percent of the total cropped area and over 80 percent of the total irrigated area is planted to rice. Approximately 96 percent share of the total cereal supply comes from rice alone (Alam and Islam, 2013, p. 257). The recent estimate of BBS (2015, p.144) accounted for about 34.71 million metric tons of rice production in Bangladesh which ranked the country as the $6^{\text {th }}$ largest rice producing country in the world as per the OECD-FAO's classification (Rahman et al., 2016).

Extension services department deserved credit for encouraging the farmers adopting modern production technologies which have enabled Bangladesh achieving nearly self-sufficient status in rice production. However, maintaining a sustainable level of production in the

\section{Cite this article}

Akter, T., Parvin, M.T., Mila, F.A. and Nahar, A. 2019. Factors determining the profitability of rice farming in Bangladesh. Journal of Bangladesh Agricultural University, 17(1): 86-91. https://doi.org/10.3329/jbau.v17i1.40668 coming decades is threatened by the tremendous growth in populations and accelerated shrinking of land size per capita. Therefore, rice production growth has to be achieved with increasingly fewer resources in land, water, chemicals, and labor (Alam and Islam, 2013).

Even though studies (such as Rahman et al., 2015 and Islam et al., 2017) have proved that rice production is a profitable farming practice in Bangladesh, the profitability may vary in different areas due to widescale adoption of modern rice technology, availability of input, the fertility of the land and so forth. Overuse of fertilizer and pesticides coupled with climate change is also causing the loss of biodiversity, loss of soil fertility, and widespread contamination of the groundwater with arsenic. The recent trends toward free trading are causing cheaper rice to enter in the local market from India, Pakistan, Philippines and many other neighboring countries which is depressing the price and creating a disincentive for local rice farmers. The interaction of all these technological, environmental, institutional factors that are part of the production, processing, marketing and consumption of rice is increasing the overall cost and lowering the profitability of rice cultivation in Bangladesh. Therefore, to what extent the profitability 
differs among different farmers' groups and which factors determine their profitability is important to estimate so that it can guide different categories of farmers determining the optimum level of production using the available resources on hand.

The available literature review suggests that there are a large numbers of similar studies (such as Inuwa et al., 2011; Rahman et al., 2015; Noonari et al., 2015; Islam et al., 2017; and Bwala and John, 2018). However, most of these studies analyzed the profitability only by descriptive analysis and not by a combination of both descriptive and econometric analysis except Rahman et al. (2015) and Islam et al. (2017). Even, the study coverage as well as the sample size were limited in these studies. From that pursuit, this study was undertaken to fill the research gap. It is expected that the systematic calculation of costs and returns, as well as the profitability of rice under this study, will add up knowledge to the researchers, policymakers as well as other interested parties who will conduct farther study on rice farming in Bangladesh. In addition, such a study may contribute to achieving the sustainable rice production system through the foreseeable future.

\section{Materials and Methods}

\section{Sampling Technique and Data Collection}

This study mainly used primary data to carry out the highlighted objectives. In doing so, it followed a multistage sampling technique for the selection of study regions and samples. In the first stage of multistage sampling, it purposively selected seven different rice producing districts viz. Barisal, Comilla, Tangail, Jessore, Bogra, Dinajpur and Habigonj covering seven divisions of Bangladesh. Using the simple random sampling technique in the second stage, furthermore, the study selected 140 rice farmers out of total 2580 from seven villages such as Raipura, Chaikot, Atharodana, Toniagara, Rainagar, Boropukur and Ratanpur under the selected districts. The study did not distinguish among Aus, Aman and Boro rice growers in selecting the sample. The primary data were collected on the respondents' socioeconomic characteristics such as age, education, family size, farm size, and literacy level as well as the rice farming practices. A structured questionnaire was used for the purpose. The data collection process covered two months period from August-September, 2016.

Besides primary data, secondary data were also collected from different sources such as the Bangladesh Bureau of Statistics (BBS), different published journals and unpublished reports, articles, and so forth. The information collected from these sources has been used to supplement different parts (such as introduction, results and discussions) of this study. Some information was needed during the selection of the study areas and samples which is difficult to summarize.

\section{Analytical Method}

The data were analyzed using both descriptive and functional analysis. Descriptive analysis was done for estimating the net profit from rice cultivation using the following profit equation was used:

$\pi=\mathrm{P}_{\mathrm{F}} \cdot \mathrm{Q}_{\mathrm{F}}+\mathrm{P}_{\mathrm{S}} \cdot \mathrm{Q}_{\mathrm{S}}-\sum\left(\mathrm{P}_{\mathrm{Xi}} \mathrm{X}_{\mathrm{i}}\right)-\mathrm{TFC}$

Where $\pi=$ net profit per hectare of rice production, $P_{F}=$ per unit price of rice $(\mathrm{BDT} / \mathrm{Kg}), \mathrm{Q}_{\mathrm{F}}=$ Quantity of rice $(\mathrm{Kg}), \mathrm{P}_{\mathrm{S}}=$ Per unit price of straw $(\mathrm{BDT} / \mathrm{Kg}), \mathrm{Q}_{\mathrm{S}}=$ Quantity of straw, $P_{X i}=$ per unit of i-th inputs used, $X_{i}=$ Quantity of i-th input used, $i=(1,2,3 \ldots \ldots \ldots n)$; and TFC $=$ Total fixed cost related to the production per hectare of rice field.

The functional analysis was carried out to identify the factors that influenced the profitability of the sampled rice farmers. The Cobb-Douglas production function model was employed following Gujarati and Porter (2008). The specification of the model is as follows:

$\mathrm{Y}=\mathrm{aX} \mathrm{i}_{\mathrm{i}}^{\mathrm{bi}}+\mathrm{e}^{\mathrm{ui}}$

Equation (1) is a non-linear equation. In order to make it linear, a natural logarithm is used on both sides as follows:

$$
\ln \mathrm{Y}=\ln \mathrm{a}+\mathrm{b}_{\mathrm{i}} \ln \mathrm{X}_{\mathrm{i}}+\mathrm{U}_{\mathrm{i}}
$$

Where,

$\mathrm{Y}=$ net profit (BDT/hectare);

$\mathrm{X}_{\mathrm{i}}=$ different socioeconomic variables such as age of the respondents (years), education (years), family size (number.), farm size (hectare), occupational status (dummy: $1=$ single, $0=$ multiple), training (dummy: $1=$ received, $0=$ not received) and farm-specific variables such as costs of power tiller (BDT/ hectare), seedling (BDT/ hectare), hired labor (BDT/ hectare), fertilizer (BDT/ hectare), irrigation (BDT/ hectare) and pesticides (BDT/ hectare); $a=$ constant or intercept term; $b_{i}=$ coefficients of the respective input variables to be estimated; and $\mathrm{U}_{\mathrm{i}}=$ Error term.

Finally, the functional model were run using the Statistical Package for the Social Sciences (SPSS) 20.

\section{Results and Discussion \\ Socio-demographic profile of the respondents}

Knowing the socio-demographic features of the farmers is important because it influences the farmers' decisionmaking ability to produce rice under different farming system. Variables such as age, education, family size, ownership pattern of land and its allocation to rice farming, farming experience, occupational status and availability of training were taken into consideration for the analyses under this study. Table 1 summarizes the socio-demographic profile of the respondents as follows:

Table 1 shows that the mean age of the rice farmers in the selected study areas was 48 years which reflects their working age as classified by BBS (2010). This group of respondent is expected to earn a higher profit due to 
being energetic and productive in the field. About 73 percent of the total respondents were literate of which majority (nearly 44\%) had a below-secondary level of education covering up to 8 years. This rate was higher than the national average literacy rate of 57.9 percent as reported in BBS (2010). On average, the rice farmer's families were composed of 6 members having an equal number of male and female. Unfortunately, this number was slightly higher than the national statistic of 5.63 as per BBS (2010). The family size can have either a positive or negative effect on the profitability of rice farming such that a farmer may incur less cost for hired labor having the advantage of a sizable large family. On the other hand, profitability may be reduced because of the increased consumption of rice by these members.

Table 1 also represents the size of land holding and its distribution. Generally, land size is used as a proxy of the wealth position of a household within the society. It is estimated that the average total land size of the studied respondents was about 0.70 hectares $^{1}$ including own land, land rented in and homestead area and excluding the land rented out. Out of the total land size, a mean of 0.57 hectares of land was used for rice farming in the selected study areas. Moreover, most of the farmers were under the small farmer's category ${ }^{2}$ according to the classification of BBS $(2015$, p.141) and they were extensively experienced (35 years) in rice farming. Small farm size is expected to contribute to lower production, thereby, lower profit whereas experienced farmers are assumed to be the higher profit earner due to their better skill and management practice in the rice field.

With regard to the occupational status, it is found that diversification was not very common in the study areas as almost 86 percent of the total respondents undertook farming as their single most livelihood mean whereas nearly 7 percent, 5 percent, and 2 percent were involved in business, job and other activities besides farming. It is assumed in this study that the rice farming profitability of those farmers who were involved in multiple occupations will be increased due to their better investment ability on the farm generated by the income earned from that multiple occupation.

Apart from the general characteristics, whether the respondents received any training or extension services were also noted. The descriptive analysis reveals that 57 percent of the respondents received such services while the rest did not. It is expected in this study that the profitability of the farmers who received training will be increased than others due to their intensive knowledge on better farming practices learned from the training or extension services.
Table 1. Socio-demographic profile of the selected rice farmers during 2016

\begin{tabular}{lc} 
Variables & $\begin{array}{c}\text { Mean values } \\
(\mathbf{N = 1 4 0 )}\end{array}$ \\
\hline Age (years) & 48 \\
Educational status (\%) & 73 \\
Mean education (years) & 8 \\
Illiterate & 27 \\
Primary & 23 \\
Secondary & 44 \\
Above secondary & 6 \\
Family size (no.) & 6 \\
Male & 3 \\
Female & 3 \\
Total land size (hectare) & 0.70 \\
Land under rice cultivation & 0.57 \\
Owned & 0.56 \\
Rented in & 0.18 \\
Rented out & 0.10 \\
Homestead & 0.07 \\
Farming experience (years) & 35 \\
Occupational status (\%) & \\
Farming as a single occupation & 86 \\
Farming + business & 7 \\
Farming + job & 5 \\
Farming+ others & 2 \\
Training or extension services $(\%)$ & \\
Received & 57 \\
Did not receive & 43 \\
\hline
\end{tabular}

Note: For the sake of convenience, the average values of the variables (except land size) are presented as an integer number.

Source: Household survey, 2016

\section{Economics of rice production}

The economics of rice production is summarized in Table 2. It presents the average total cost, total return, gross margin, net return and the benefit-cost ratio (BCR) of producing rice in different study areas among different farmer's category. The variable cost items included the cost of power tiller, seedling, human labor, fertilizer, manure, irrigation, pesticides, and miscellaneous cost items. Interest on operating capital was also included in the variable cost items. On the other hand, land use cost was recorded as the fixed cost of rice farming. On average, rice farmers incurred a total cost equals BDT 59994 which was the summation of total variable cost (BDT 56727) and fixed cost (BDT 3267). Obviously, there was a significant variation of the total costs incurred per hectare by small (BDT 13266) and medium (BDT 18887) farmers than large farmers (BDT 27841).

The return items included both the main products and by-product (i.e. straw) of rice which is calculated by multiplying the total amount of production with the respective market prices. The estimation reveals that per hectare average return from rice farming for all respondents was BDT 82195. The gross margin of rice has been calculated by deducting the total variable cost from the total return which was BDT 25468 per hectare. The net return of rice is also calculated to evaluate the profitability of producing rice which is estimated at BDT 22201 during 2016. All these figures were noticeably larger for the large farmers than small and medium farmers.

\footnotetext{
${ }^{\mathrm{T}} 1$ hectare $=2.47$ acres

${ }^{2}$ Classification of farm size: small (0.05-2.49 acres), medium (2.50-7.49 acres), large ( 7.50 acres and above)
} 
The final economic measure is the calculation of BCR (undiscounted) which is generally used to compare benefits per unit of cost. The BCR is generally calculated as the ratio of total returns and total cost which is equal to 1.37 for all farmers in the study areas during 2016. It implies that BDT 1.37 would be earned by investing BDT 1.00 on rice farming, thereby, it indicates that rice is a profitable farming activity. However, this estimation also differs among the farmer's groups by $1.19,1.40$ and 1.43 respectively.

Table 2. Average cost and return of rice production (BDT/hectare) in the selected study areas during 2016

\begin{tabular}{|c|c|c|c|c|}
\hline Items of cost and return & $\begin{array}{c}\text { All respondents } \\
(\mathrm{N}=140)\end{array}$ & $\begin{array}{l}\text { Small farmers } \\
\qquad(\mathrm{N}=65)\end{array}$ & $\begin{array}{c}\text { Medium farmers } \\
(\mathrm{N}=\mathbf{5 8})\end{array}$ & $\begin{array}{l}\text { Large farmers } \\
(\mathrm{N}=17)\end{array}$ \\
\hline Total variable cost (TVC) & 56727 & 12720 & 17689 & 26318 \\
\hline Power Tiller & 7544 & 1836 & 2311 & 3397 \\
\hline Seedlings & 2583 & 661 & 785 & 1137 \\
\hline Human labor & 27037 & 6840 & 8196 & 12001 \\
\hline Fertilizer & 10915 & 2358 & 2827 & 5729 \\
\hline Irrigation & 5974 & 1523 & 2105 & 2346 \\
\hline Pesticides & 1928 & 530 & 673 & 725 \\
\hline Interest on operating capital & 746 & 347 & 90 & 309 \\
\hline Total fixed cost (land use cost) & 3267 & 546 & 1198 & 1523 \\
\hline Total cost (TC) & 59994 & 13266 & 18887 & 27841 \\
\hline Total return (TR) & 82195 & 15795 & 26512 & 39887 \\
\hline Main product & 77316 & 13392 & 21947 & 37977 \\
\hline By-product & 4879 & 1403 & 1565 & 1910 \\
\hline Gross margin (GM) & 25468 & 3075 & 8823 & 13570 \\
\hline Net return (NR) & 22201 & 1529 & 7625 & 12046 \\
\hline Benefit cost ratio (BCR) & 1.37 & 1.19 & 1.40 & 1.43 \\
\hline
\end{tabular}

Source: Field survey, 2016

\section{Econometric analysis}

The findings of the estimated Cobb- Douglas production function for rice is presented in Table 3. In this function, the net return of rice has been used as the dependents variable. The functional analysis reveals that out of twelve explanatory variables, the cost of power tiller, hired labor and fertilizer played a significant role in determining the level of profit earned from rice cultivation for all the farmers in different study areas. The coefficient signs of all the significant variables are positive which implies that an additional unit increase in these costs will increase the profit from rice farming by the coefficient values associated with these variables (Table 3). The best plausible explanation of these results could be that if the farmers are able to afford these input costs in an efficient manner, they will also be able to generate a larger volume of production as well as sales. Therefore, the net value of return will also be high. The model further reveals that the estimated coefficients of labor and fertilizer costs are significant at 1 percent level whereas it is significant at 5 percent level for the cost of power tiller. These findings of labor and fertilizer are found to be consistent with Rahman et al. (2015) and Islam et al. (2017). However, the finding for power tiller cannot be supported by any of these two studies as the authors did not use this variable in their model estimation.

Using the information from Table 3, the estimated production function for rice can be represented as follows:

$$
\begin{aligned}
& \ln Y=1.86-0.09 \ln \mathrm{X}_{1}+0.02 \ln \mathrm{X}_{2}+0.07 \ln \mathrm{X}_{3}-0.02 \ln \mathrm{X}_{4} \\
& -0.02 \ln \mathrm{X}_{5}+0.02 \ln \mathrm{X}_{6}+0.15 \ln \mathrm{X}_{7}+0.01 \ln \mathrm{X}_{8}+0.40 \ln \mathrm{X}_{9}
\end{aligned}
$$

$$
+0.42 \ln \mathrm{X}_{10}+0.02 \ln \mathrm{X}_{11}+0.04 \ln \mathrm{X}_{12}+\mathrm{U}_{\mathrm{i}}
$$

In addition to the model estimation for all farmers, three separate models were also run for small, medium and large farmers to find out whether the same factors determine the rice farming profitability and whether the effect of these variables is unique across the groups. The results show that the use of only two inputs such as fertilizer and irrigation significantly and positively determined the small farmers' profitability from the rice farming.

On the other hand, farm size negatively and age and the costs of power tiller, labor and fertilizer were positively correlated with the level of profitability for the medium farmers. The positive value of the age variable implies that the net profit will be increased by 34 percent due to the addition of one year into the age of the respondents. The best explanation of this result would be that as the farmers gets older, they are better able to manage the farm due to their increased farming experience gained through age, thus, profitability from farming. The negative sign of farm size indicates that if the farm size increases, the farm profitability through rice cultivation will be reduced by 2 percent for the medium farmers. This result is quite unanticipated, however, the reason could be that if the farm size increases for this group of farmers, they might use the increased land for other farming activities which are more profitable than rice.

In contrast to the medium farmers, variable age has been identified as a significant negative determinant whereas the cost of fertilizer has been estimated with a positive sign. The identification of the fertilizer cost as a significant positive determinant is quite normal and the interpretation is also quite straightforward. However, the 
result of age proves disappointing as the study expected a positive coefficient value for this variable. It can further be explained as that as the large farmers are already rich, they will be more interested on large investment (probably buying land, jewelry, producing cash crop and the likes) than rice farming as they will get older.

Moreover, to what extent the findings of the three groups of farmers support or deviates from the existing literature cannot be presented in this study because none of the studies reviewed so far is found to differentiate the impact across different farmers' groups.

Table 3 also presents the F-value, $\mathrm{R}^{2}$, adjusted $\mathrm{R}^{2}$ and elasticity of rice production. The F-values of the estimated models is 23.94 for all farmers, 5.38, 10.82 and 6.75 for small, medium and large farmers respectively all of which are significant. It implies that all the explanatory variables used in this study were important for explaining the variations in returns of rice across different farmers' group. The values of $\mathrm{R}^{2}$ and adjusted $\mathrm{R}^{2}$ are also sufficiently larger than 0.5 for the different groups, thereby, indicates the proportion of variation that can be explained by the variables used in the model estimation.

The final result is the calculation of elasticity of production which refers to the percentage change in output in relation to the percentage change in input. The concept of elasticity is applied to the production function to determine the stage in which farmers were allocating their resources. The coefficient of Cobb- Douglas production function gives the direct elasticity measurement and their summation indicates the returns to scale of production (Table 3). In this study, the elasticity has been calculated by summing up the coefficients of only production-specific variables (that is power tiller, seedling, labor, fertilizer, irrigation, and pesticide) and excluding the coefficient of householdspecific variables (that is age, education, family size, farm size, occupational and training status). The estimated elasticity for total samples is 1.04 which is greater than 1. It implies that rice growers were in increasing returns to scale where rice output increases at a rate that is greater than the input use rate. More clearly, the farmers still have the scope to allocate more inputs in their rice field as it will generate a higher return than production cost. Among the farmers' category, Table 3 shows that medium farmers were also in increasing return to scale (1.21) whereas small (0.84) and large farmers' $(0.77)$ production pattern exhibited a decreasing return to scale. It means that the small and large farmers were already the rational producers in the study areas through the proper utilization of their existing resources. Therefore, the additional use of the input in their field may results in inefficiency of resource use and thus, will significantly reduce their farm profit.

Table 3. Results of the econometric analysis

\begin{tabular}{|c|c|c|c|c|c|c|c|c|}
\hline \multirow[t]{2}{*}{$\overline{\text { Explanatory variables }}$} & \multicolumn{2}{|c|}{$\begin{array}{l}\text { All farmers } \\
(\mathrm{N}=140)\end{array}$} & \multicolumn{2}{|c|}{$\begin{array}{c}\text { Small farmers } \\
(N=65)\end{array}$} & \multicolumn{2}{|c|}{$\begin{array}{c}\text { Medium farmers } \\
(\mathrm{N}=58)\end{array}$} & \multicolumn{2}{|c|}{$\begin{array}{c}\text { Large farmers } \\
(\mathrm{N}=17)\end{array}$} \\
\hline & Coefficients & Elasticity & Coefficients & Elasticity & Coefficients & Elasticity & Coefficients & Elasticity \\
\hline Intercept & $\begin{array}{l}1.86^{* *} \\
(0.79)\end{array}$ & 1.86 & $\begin{array}{c}3.69 * * * \\
(1.37)\end{array}$ & 3.69 & $\begin{array}{l}-1.22 \\
(1.26)\end{array}$ & -1.22 & $\begin{array}{l}8.77 * \\
(3.52)\end{array}$ & 8.77 \\
\hline Age (years) & $\begin{array}{l}-0.09 \\
(0.12)\end{array}$ & -0.09 & $\begin{array}{l}-0.18 \\
(0.19)\end{array}$ & -0.18 & $\begin{array}{l}0.34 * \\
(0.20)\end{array}$ & 0.34 & $\begin{array}{c}-0.94 * * \\
(0.35)\end{array}$ & -0.94 \\
\hline $\begin{array}{l}\text { Education (years of } \\
\text { schooling) }\end{array}$ & $\begin{array}{c}0.02 \\
(0.04)\end{array}$ & 0.02 & $\begin{array}{c}0.06 \\
(0.06)\end{array}$ & 0.06 & $\begin{array}{c}0.06 \\
(0.06)\end{array}$ & 0.06 & $\begin{array}{l}-0.16 \\
(0.24)\end{array}$ & -0.16 \\
\hline Family size (no.) & $\begin{array}{c}0.07 \\
(0.08)\end{array}$ & 0.07 & $\begin{array}{c}0.14 \\
(0.15)\end{array}$ & 0.14 & $\begin{array}{c}0.12 \\
(0.14)\end{array}$ & 0.12 & $\begin{array}{l}-0.28 \\
(0.21)\end{array}$ & -0.28 \\
\hline Farm size (hectare) & $\begin{array}{l}-0.02 \\
(0.05)\end{array}$ & -0.02 & $\begin{array}{l}-0.02 \\
(0.14)\end{array}$ & -0.02 & $\begin{array}{l}-0.35^{*} \\
(0.20)\end{array}$ & -0.35 & $\begin{array}{l}-0.03 \\
(0.26)\end{array}$ & -0.03 \\
\hline $\begin{array}{l}\text { Occupational status (dummy: } \\
1=\text { single }, 0=\text { multiple) }\end{array}$ & $\begin{array}{l}-0.02 \\
(0.07)\end{array}$ & -0.02 & $\begin{array}{c}0.04 \\
(0.12)\end{array}$ & 0.04 & $\begin{array}{l}-0.04 \\
(0.11)\end{array}$ & -0.04 & $\begin{array}{l}-0.33 \\
(0.34)\end{array}$ & -0.03 \\
\hline $\begin{array}{l}\text { Training (dummy: } 1= \\
\text { received, } 0=\text { otherwise) }\end{array}$ & $\begin{array}{c}0.02 \\
(0.05)\end{array}$ & 0.02 & $\begin{array}{c}0.04 \\
(0.12)\end{array}$ & 0.04 & $\begin{array}{c}0.16 \\
(0.14)\end{array}$ & 0.16 & $\begin{array}{c}0.27 \\
(0.21)\end{array}$ & 0.27 \\
\hline Power tiller cost (BDT/hec.) & $\begin{array}{c}0.15^{* *} \\
(0.07)\end{array}$ & 0.15 & $\begin{array}{c}0.12 \\
(0.10)\end{array}$ & 0.12 & $\begin{array}{c}0.32 * * * \\
(0.12)\end{array}$ & 0.32 & $\begin{array}{l}-0.34 \\
(0.37)\end{array}$ & -0.34 \\
\hline Seedling cost BDT/hec.) & $\begin{array}{c}0.01 \\
(0.05)\end{array}$ & 0.01 & $\begin{array}{c}0.08 \\
(0.13)\end{array}$ & 0.08 & $\begin{array}{c}0.02 \\
(0.06)\end{array}$ & 0.02 & $\begin{array}{c}0.58 \\
(0.40)\end{array}$ & 0.58 \\
\hline Hired labor cost (BDT/hec.) & $\begin{array}{l}0.40 * * * \\
(0.11)\end{array}$ & 0.40 & $\begin{array}{c}0.17 \\
(0.21)\end{array}$ & 0.17 & $\begin{array}{l}0.35^{* *} \\
(0.16)\end{array}$ & 0.35 & $\begin{array}{c}0.06 \\
(0.60)\end{array}$ & 0.06 \\
\hline Fertilizer cost (BDT/hec.) & $\begin{array}{c}0.42 * * * \\
(0.06)\end{array}$ & 0.42 & $\begin{array}{c}0.31 * * * \\
(0.10)\end{array}$ & 0.31 & $\begin{array}{c}0.48 * * * \\
(0.10)\end{array}$ & 0.48 & $\begin{array}{l}0.61 * \\
(0.24)\end{array}$ & 0.61 \\
\hline Irrigation cost (BDT/hec.) & $\begin{array}{c}0.02 \\
(0.01)\end{array}$ & 0.02 & $\begin{array}{c}0.09 * * * \\
(0.03)\end{array}$ & 0.09 & $\begin{array}{l}-0.01 \\
(0.02)\end{array}$ & -0.01 & $\begin{array}{c}0.01 \\
(0.05)\end{array}$ & 0.01 \\
\hline Pesticides cost (BDT/hec.) & $\begin{array}{c}0.04 \\
(0.05)\end{array}$ & 0.04 & $\begin{array}{c}0.07 \\
(0.07)\end{array}$ & 0.07 & $\begin{array}{c}0.05 \\
(0.10)\end{array}$ & 0.05 & $\begin{array}{l}-0.15 \\
(0.34)\end{array}$ & -0.15 \\
\hline$\overline{\text { F-value }}$ & 23.94 & & 5.38 & & 10.82 & & 6.75 & \\
\hline & 0.8 & & 0.7 & & 0.7 & & 0.9 & \\
\hline Adjusted $R^{2}$ & 0.6 & & 0.5 & & 0.6 & & 0.8 & \\
\hline Returns to scale $\left(\sum b_{i}\right)$ & 1.0 & & 0.8 & & 1.2 & & 0.7 & \\
\hline
\end{tabular}

Note: Figures in the parenthesis indicates the standard error

*** significant at 1 percent level, ** significant at 5 percent level, *significant at 10 percent level

Source: Author's estimation (2016) 


\section{Conclusion and Policy Recommendations}

Rice, being the staple food for almost all the population in Bangladesh, plays a significant role in the agricultural development and food security. Even though the soil and the sub-tropical climatic condition are favorable for rice cultivation in this country, ensuring food security in the face of limited land size per household poses a serious challenge for the Government of Bangladesh (GoB). Combined with this problems, most of the farmers are deprived of the advantages of modern varieties of seed, fertilizer, pesticides as well as modern technologies which affect the productivity as well as the profitability of rice per hectare. The findings reveal that rice farming is a profitable activity in Bangladesh. However, the level of profit is significantly higher for large farmers than small and medium farmers. The functional analysis reveals that different factors determine the level of profit from rice farming across different groups. Among them, the cost of fertilizer is a common concern for all the groups of farmers. Even though the government has subsidized the fertilizer price, whether there is the timely procurement of such services by the needy farmers or not should be monitored through different ministries and departments. As rice farming is a profitable activity in Bangladesh and it is a country of natural disaster, different research organizations should develop rice varieties, that are resistant to the adverse climatic condition. In addition, the government can maintain collaboration with different private and research organizations so that they can come up with better and affordable technology for the rice farmers. Extension department can also play a role in providing training on modern technology use and strengthen the field demonstration process to suggest a better combination of input use for higher return. Extended credit facilities will also help the farmers adopting different technologies to prevent the losses before and after the harvest. Overall, a fair price policy should be designed to control price fluctuation of rice so that the farmers can earn a higher profit from selling their crops. If all those suggestions are well taken, Bangladesh may become food secured and self-sufficient in rice cultivation soon.

\section{Acknowledgment}

The authors are very grateful to the respondents for providing valuable data for conducting this study.

\section{Funding}

This study was funded by USDA under the research project "Measuring the Value of Improved Grain Measurement in Bangladesh" implemented by the Department of Agricultural Economics, Bangladesh Agricultural University, Mymensingh-2202, Bangladesh.

\section{References}

Alam, M. S. and Islam, M. A. 2013. Long-Term Assessment of Rice Production Scenario in Bangladesh: A Macro Dynamics. Bangladesh Journal of Agricultural Research, 38(2): 257-269.

BBS (Bangladesh Bureau of Statistics). 2010. Report on the Household Income and Expenditure Survey 2010. Statistics and Informatics Division, Ministry of Planning, Government of the People's Republic of Bangladesh.

BBS (Bangladesh Bureau of Statistics). 2015. Statistical Pocketbook Bangladesh 2015. Statistics and Informatics Division, Ministry of Planning, Government of the People's Republic of Bangladesh.

Bwala, M. A., and John, A. U. 2018. Profitability Analysis of Paddy Production: A Case of Agricultural Zone 1, Niger State Nigeria. Journal of Bangladesh Agricultural University, 16(1): 88-92. https://doi.org/10.3329/jbau.v16i1.36486

Gujarati D. N. and Porter, D. C. 2008. Basic Econometrics., 5th edition. New York, NY: McGraw-Hill/Irwin.

Inuwa, I. M. S., Kyiogwom, U. B., Ala, A. L., Maikasuwa, M. A., and Ibrahim, N. D. 2011. Profitability Analysis of Rice Processing and Marketing in Kano State, Nigeria. Nigerian Journal of Basic and Applied Science, 19(2): 293-298.

Islam, Z., Begum, R., Sharmin, S., and Khan, A. 2017. Profitability and Productivity of Rice Production in Selected Coastal Area of Satkhira District in Bangladesh. International Journal of Business, Management and Social Research, 03(01): 148-153.

Noonari, S., Irfana, M., Memon, N., Jatoi, A. A., Bux, M., Bhatti, M. A., Shah, T. 2015. Analysis of Rice Profitability and Marketing Chain: A Case Study of District Analysis of Rice Profitability and Marketing Chain: A Case Study of District Sukkur Sindh Pakistan, (September). International Journal of Business and Economics Research, 4(3): 133-143, https://doi.org/10.13140/RG.2.1.4152.1121.

Rahman, F., Shammi, S. A., Parvin, M. T., Akter, N., Khan, M. S., and Haque, S. 2016. Contribution of Rural Women to Rice Production Activities in Two Different Areas of Bangladesh. Progressive Agriculture, 27(2): 180-188.

Rahman, M. C., Nafisa, C. N. B. Hossain, M. R., Rahaman, M. S. and Chowdhury, A. 2015. Comparative Profitability and Efficiency Analysis of Rice Farming in the Coastal Area of Bangladesh: The Impacts of Controlling Saline Water Intrusion. IOSR Journal of Agriculture and Veterinary Science, 8(10): 89-97. http://doi.org/10.9790/2380-081028997 